\title{
Environmental sensitivity to mosquito transmitted diseases in El-Fayoum using spatial analyses
}

\author{
Asmaa M. El-Hefni, Ahmed M. El-Zeiny", and Hala A. Effat \\ Environmental Studies and Land Use Division, National Authority for Remote Sensing and Space Sciences (NARSS), Cairo, Egypt
}

\begin{abstract}
El-Fayoum governorate has unique characteristics which induces mosquito proliferation and thus increased the risk arisen from diseases transmission. Present study explores the role of remote sensing and GIS modeling integrated with field survey for mapping mosquito breeding sites and the areas under risk of diseases transmission in El-Fayoum governorate. Entomological surveys were conducted for a total number of 40 accessible breeding sites during the period 12-16 November 2017. A calibrated Landsat OLI image, synchronized with the field trip, was processed to produce Normalized Difference Vegetation Index (NDVI), Normalized Difference Moisture Index (NDMI), and Land Surface Temperature (LST). A cartographic GIS model was generated to predict breeding sites in the whole governorate and to assess the potential risk. The main filarial disease vector (Culex pipiens) was abundant at Atsa district, while Malaria vectors (Anopheles sergentii and Anopheles multicolor) were mainly distributed in El-Fayoum and Youssef El-Seddiq districts. Means levels of NDVI, NDMI and LST at breeding habitats were recorded; $0.18,0.08$ and $21.75^{\circ} \mathrm{C}$, respectively. Results of the model showed that the highest predicted risk area was reported at Atsa district $\left(94.4 \mathrm{~km}^{2}\right)$ and Yousef El-Sediq $\left(81.8 \mathrm{~km}^{2}\right)$ while the lowest prediction was observed at Abshawai district $\left(35.9 \mathrm{~km}^{2}\right)$. It can be concluded that Atsa, Yousef El-Sedik and El-Fayoum districts are more vulnerable to Malaria and Filaria diseases outbreaks, thus precaution and pest control methods must be applied to mitigate the possible risks.
\end{abstract}

\section{Introduction}

El-Fayoum Governorate is particular in its nature which is differing from the Upper Egypt, Delta and the Oasis. It is characterized by being lower than sea level and by gradual decrease in elevation. The governorate is inhabited by 1.2 million people mostly work in agricultural lands and related industries. The favorable temperature and relative humidity of the Governorate lead to the extension of the disease transmission season to eight months a year from the end of March to the end of November [1].

Only El-Fayoum Governorate was identified as a high risk area for dangerous malaria, other areas in Egypt may be vulnerable, particularly Aswan and Cairo governorates. During 1971-2004, indigenous malaria cases were recorded [2] while during the period 2001-2010, the imported malaria cases were recorded. During the period (2007-2014), Abshawai district was inhabited with the highest number of imported malaria cases, followed by El-Fayoum then Snorus district. These cases were imported from African countries especially Sudan [3]. The importation of malaria refers to infections acquired outside and brought into non-endemic countries [4]. The spatial variation in malarial distributions can be attributed to variations in environmental conditions (land cover, temperature, precipitation) and human population distribution that disease vectors depend on for survival [5].

The main problem in dangerous malaria prevalence in El-Fayoum Governorate is the high level of subsoil water leading to formation of several pools and swamps creating preferable environmental conditions for Anopheline vectors [6]. Anopheles pharoensis Theobald, Anopheles multicolar Cambouliu and Anopheles sergentii (Theobald) are common mosquito species and efficient vectors of malaria in El-Fayoum Governorate, where Plasmodium vivax and Plasmodium falciparum are endemic. The population ecology of culicine mosquitoes in two villages of El-Fayoum Governorate was evaluated in coordination with malaria vectors studies [7]. Malaria parasite was reevaluated and studied considering the environmental factors affecting malaria status in ElFayoum [3].

Climate change may contribute to the resurgence of malaria in areas where the public health infrastructure is insufficient (e.g., in rural areas). Therefore, El-Fayoum should take special attention. Understanding of both environmental parameters of mosquito habitats and their spatial/temporal distribution have been shown to be an effective approach for reducing mosquito-borne disease endemicity $[8,9]$.

Integration between Remote Sensing and Geographical Information System (GIS) could successfully be utilized to predict the habitat

* Corresponding author: aelzeny@ narss.sci.eg 
appropriateness, which can help in designing optimal mosquito vector control strategies based on precise spatial/temporal information database [10]. Consequently, most of the developed countries are applying these systems to develop their own levels of policy to mitigate mosquito problems.

Globally, several studies have successfully utilized geospatial techniques in environmental studies of mosquito [11-24]. In Egypt, few studies make an effort to predict the potential mosquito breeding habitats by using geospatial techniques in some Egyptian Governorates [17, 25-27]. These studies are likely to be used widely in mosquito control programs in the future [28]. Present study aims to assess and map areas under risk of mosquito transmitted diseases in El-Fayoum using geospatial techniques.

\section{Materials \& methods}

\subsection{Study area}

El-Fayoum Depression appears as a large oasis in the Egyptian Western Desert, which is directly connected to the River Nile through Bahr Youssef. It lies between latitudes $28^{\circ} 55^{\prime} \mathrm{N}$ and $29^{\circ} 40^{\prime} \mathrm{N}$, longitude $29^{\circ} 55^{\prime} \mathrm{E}$ and $31^{\circ} 5^{\prime} \mathrm{E}$ (Figure 1). The total area of El Fayoum Governorate occupies $5794.59 \mathrm{~km}^{2}$ including two artificial lakes (Wadi El-Rayan), in addition to the natural Lake Qaroun. The meteorological data indicate that the annual average rainfall is $8 \mathrm{~mm}$, with some years of no rainfall at all, while in some cases as much as $44 \mathrm{~mm}$ rain falls in 1 day. The minimum average temperature in summer is $22^{\circ} \mathrm{C}$, while the maximum is $38^{\circ} \mathrm{C}$ or higher (up to $50^{\circ} \mathrm{C}$ ) [29]. Relative humidity records indicate monthly variations between 42.6 and $67.4 \%$, and the average annual humidity is $55 \%$ [30]. Dryness prevails all over the year throughout El-Fayoum Governorate and the climate of this area is arid [31]. Governorate includes six administrative districts, namely, Fayoum, Tamia, Atsa, Snorus, Abshway, and Yousef El Seddik.

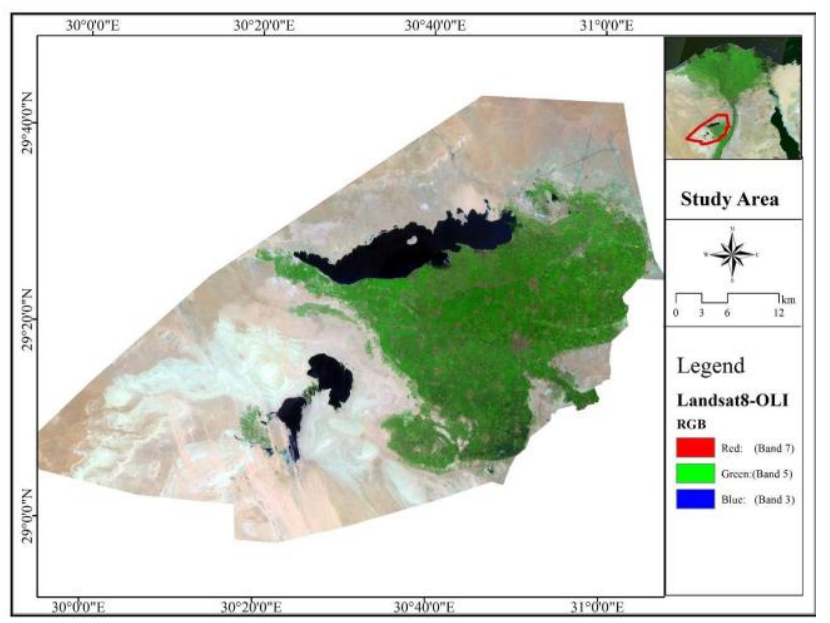

Fig. 1. Location map of El-Fayoum Governorate

\subsection{Mosquito larval collection}

Entomological surveys were conducted to all accessible breeding sites as illustrated in Fig. (2). Mosquito's larvae were collected by a standard dipper from stagnant aquatic habitats. From each breeding site, 5 dips were taken around. Collected larvae were preserved in $70 \%$ Ethyl Alcohol; the larvae were permanently prepared on slides and taxonomically identification using the Keys of [32] Natural and physical characteristics of each habitat site were described and recorded as an intensity of light, presence and types of vegetation, a condition of the water (Fig.3).
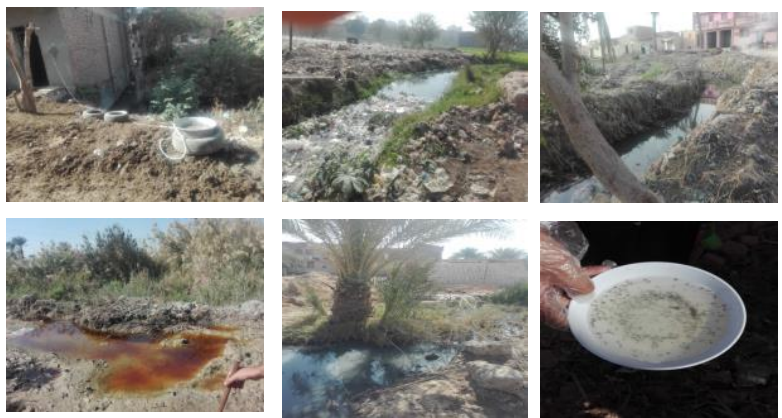

Fig. 2. Study area showing mosquito breeding habitats

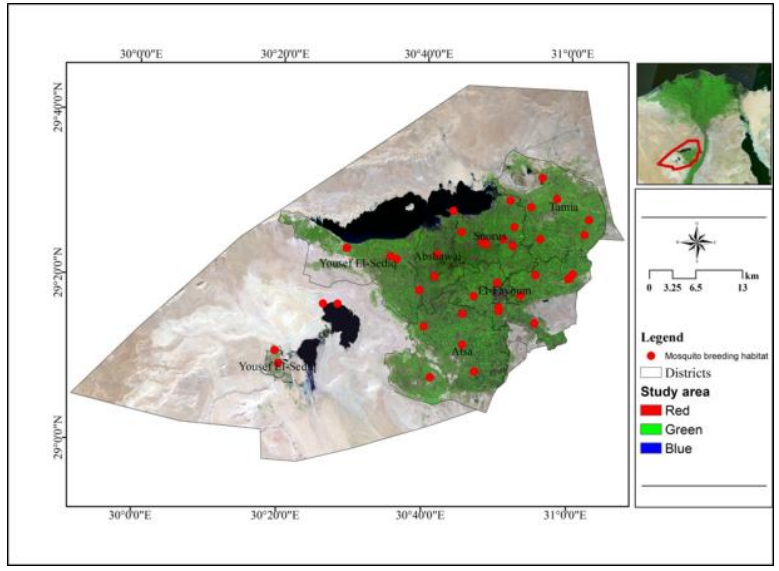

Fig. 3. Different mosquito breeding habitats in El-Fayoum Governorate as captured from the field

\subsection{Satellite images acquisition \& pre- processing}

Multispectral Landsat-8 (OLI) image acquired at November 2017 was freely downloaded from http://glovis.usgs.gov/ for El-Fayoum Governorate. The study area is located in two scenes; $177-39 \& 177-40$ and acquired as raw data. Radiometric calibration and atmospheric correction were applied for each scene separately to correct radiometric errors and spectral distortions in the image, A georeferenced mosaic was produced and the corrected image was resized to subset the study area.

\subsection{Satellite image processing}

To assess the resources and activities in the study area, the calibrated image was classified using Maximum 
likelihood classifier and all relevant networks (i.e.g irrigation, drainage and roads) were added to produce Land use/Cover (LULC) map. Four main LULC classes were obtained; urban, vegetation, water and bare lands. The accuracy of the classified image exceeded $90 \%$ on basis on ground verification points.

To determine the preferable predictor of mosquito habitat; Normalized Difference Vegetation Index (NDVI), Normalized Difference Moisture Index (NDMI) and Land Surface Temperature (LST) were estimated from the calibrated Landsat- 8 image.

NDVI is determined using the Red and near-infrared (NIR) bands of a given image [33] and is expressed as follow:

$$
N D V I=(N I R-R e d) /(N I R+R e d)
$$

NDMI correlates with soil moisture. It contrasts nearinfrared (NIR) band, which is sensitive to reflectance of leaf chlorophyll and to mid-infrared (SWIR). Values higher than 0.1 indicate to high humidity level, while low levels (close to -1) signify low humidity content [34] and is expressed as;

$$
N D M I=(N I R-S W I R) /(N I R+S W I R)
$$

LST was calculated by applying a mathematical algorithm, using brightness temperature of thermal bands (B10\&11) of TIRS sensor as well as mean and difference in Emissivity (LSE) factor derived from (FVC) of optical bands of OLI sensor for estimating LST of an area [35]. The algorithm is:

$$
\begin{gathered}
L S T=T B 10+C 1(T B 10-T B 11)+C 2(T B 10-T B 11)^{2}+ \\
C 0+(C 3+C 4 W)(1-m)+(C 5+C 6 W) \Delta m)
\end{gathered}
$$

Where,

LST: Land Surface Temperature (Kelvin)

TB10 and TB11: Brightness Temperature of (B10\&11) (Kelvin)

C0-C9: Split-Window coefficient values [36, 37].

$m$ : Mean LSE

$\Delta m$ : Difference of LSE

$W:$ Atmospheric water-vapor content $=0.013$

\subsection{Adopted methodology and GIS modeling}

A cartographic model was developed to predict the potential mosquito habitats on basis of mosquito habitat characterization. The three selected environmental variables (NDVI, NDMI and LST) were reclassified considering their levels in mosquito breeding sites. Then, weighted Overlay GIS model were generated. It can weigh the values of each dataset and combine them to create risk map (Fig.4).

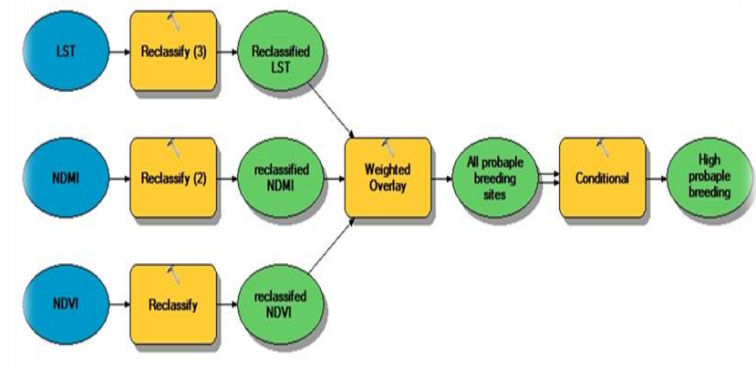

Fig. 4. Diagram showing the adopted predictive model

\subsection{Data Analysis}

The statistical data analysis was done using SPSS software (version 19 for windows). Mean densities among each habitat types were analyzed using One-way analysis of variance (ANOVA). Multiple Regression analysis was done to obtain the best environmental predictor (NDVI, NDMI, and LST) affecting the abundance for each larval species.

\section{Results}

\subsection{LULC map}

LULC map showed that El-Fayoum Governorate is bordered from north and west by the western desert which represents the most dominant class exhibiting $61.77 \%$ (3579.33 $\mathrm{Km}^{2}$ ) as shown in Fig.(5). Agricultural area (i.e. Old and newly reclaimed areas) represented the second dominant class; representing $1633.86 \mathrm{Km}^{2}$ $(28.20 \%)$. Irrigation and drainage canals are well distributed in the agricultural lands. Water bodies are mainly represented by Qaroun and Wadi El-Rayan lakes amounting $345.46 \mathrm{Km}^{2}(5.96 \%)$ from the total area of the governorate. The urbanized areas occupy $235.94 \mathrm{Km}^{2}$ $(4.07 \%)$ and were embedded in the agricultural area connected with dense roads networks particularly in the low depression area. The combination on these LULC classes within the studied area induces the proliferation of mosquito and increase the suitability of habitats for mosquito to bread.

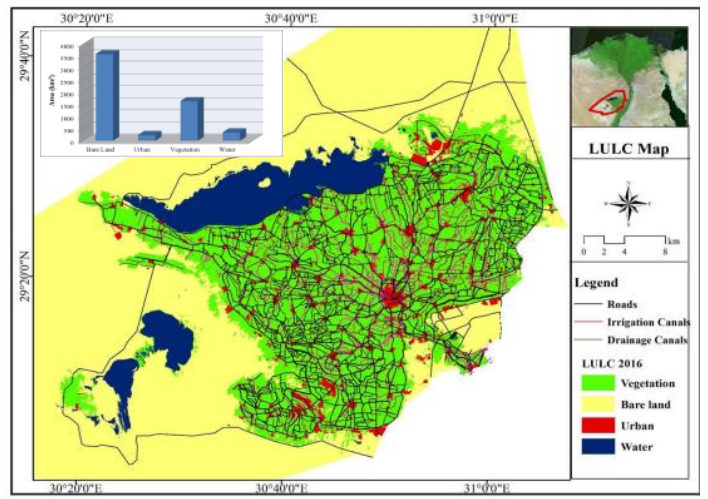

Fig. 5. LULC map for El-Fayoum Governorate 


\subsection{Relative abundance of mosquito larval species}

Mosquito breeding habitat were surveyed during 12-16 November 2017, where 40 visited sites were inspected for larvae. The breeding habitats inspected, during the period of the study area, were categorized into six larval habitat types; sewage, seepage, drainage canals, irrigation canals, agriculture drainage canals and unsealed cesspools. From surveying results, six mosquito species namely; Culex pipiens, Culex perexiguus, Ochlerotatus caspius, Ochlerotatus detritus, Anopheles multicolor and Anophele sergentii were distributed in the study area. Culex pipiens was the most abundant (92\%) of the total species, while the least abundant species was Anophele sergentii (0.2\%) (Table 1, Fig.6).

Table 1. Relative abundance of mosquito larval species at November, 2017

\begin{tabular}{|c|c|c|}
\hline Species & No. & Density \\
\hline Cx. Pipiens & 3733 & 754.8 \\
\hline Cx.perexiguus & 68 & 21.8 \\
\hline Oc. Caspius & 20 & 1.2 \\
\hline Oc. Detritus & 178 & 39.8 \\
\hline An. multicolor & 6 & 1.2 \\
\hline An. sergentii & 1 & 0.2 \\
\hline Total & $\mathbf{4 0 0 6}$ & $\mathbf{8 1 9}$ \\
\hline
\end{tabular}

Table 2. Density of mosquito larval species collected from each breeding habitats

\begin{tabular}{|l|c|c|c|c|c|c|}
\hline \multicolumn{1}{|c|}{ Habitat Type } & Cx. pipiens & Cx. perexiguus & Oc. detritus & Oc. caspius & An. sergentii & An. multicolor \\
\hline Drainage canals & 305.6 & 0 & 0 & 0 & 0 & 0 \\
\hline Sewage & 70.0 & 0 & 0 & 0 & 0 & 0 \\
\hline Agriculture drainage & 334.8 & 16.8 & 25.0 & 0 & 0.2 & 0.2 \\
\hline Seepage & 2.8 & 0.2 & 10.4 & 1.2 & 0 & 0 \\
\hline Irrigation canal & 20.2 & 4.8 & 3.2 & 0 & 0 & 1 \\
\hline Unsealed cesspool & 21.4 & 0 & 1.2 & 0 & 0 & 0 \\
\hline
\end{tabular}

Survival and distribution of mosquitoes are significantly influenced by different environmental variables as humidity, temperature, vegetation and availability of suitable larval habitats.

Spatial distribution maps of NDVI, NDMI and LST showed that NDVI ranged from (-0.9 to 0.8) while NDMI from ( -0.8 to 1$)$ and LST showed a fluctuation between $\left(19\right.$ and $\left.36^{\circ} \mathrm{C}\right)$ as illustrated in Figs. 7 A, B,C.

Environmental variables are important for both diseases transmission and for maintaining breeding sites for the mosquito vector. Means of NDVI, NDMI and LST at different breeding habitats were extracted to characterize mosquito breeding habitats, recording $(0.24$, 0.03 and $26.02{ }^{\circ} \mathrm{C}$ respectively) as illustrated in Table (4).

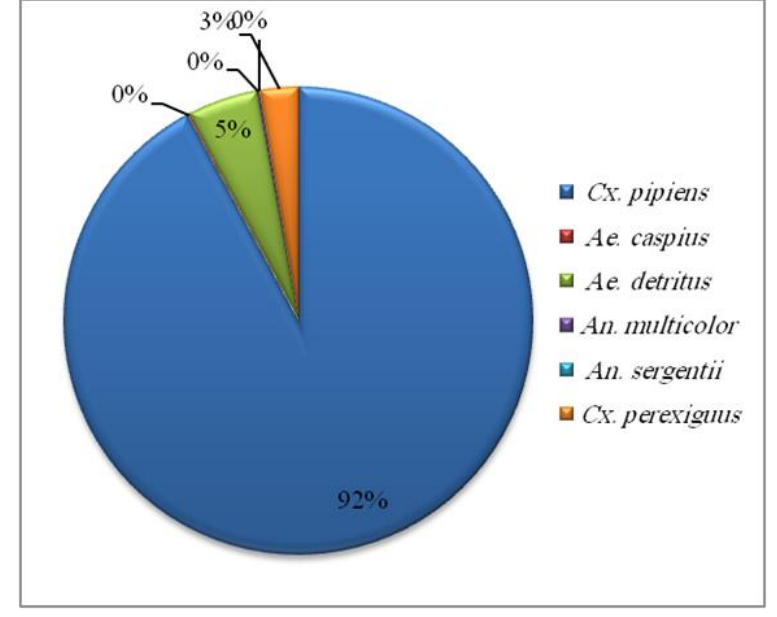

Fig. 6. Relative abundance of mosquito larval species

Different inspected mosquito breeding habitats during the study period were categorized into six habitat types (Table 2). Cx. pipiens was recorded in the six breeding habitats with various densities. $C x$. pipiens, $C x$. perexiguus, Oc. detritus, An. multicolor and An. sergentii were co-existed together at agriculture drainage habitat.

As showed in Table (3) the main filarial vector, Culex pipiens, was recorded at all districts with high density at Atsa district. Malaria vectors; Anopheles sergentii, was collected only from El-Fayoum district, while Anopheles multicolor was found at Tamia and Youssef El-Seddiq districts.

\subsection{Model generation and risk assessment}

The model was generated to predict the potential mosquito breeding habitats considering the optimal values of NDVI, NDMI and LST at breeding sites in the study area. Urbanization represented the high risk area; 2-kilometer buffer zone around the predicted larval habitat served to determine the areas at risk of mosquito proliferation. Further, suitable sites in regard of environmental conditions without a recorded larva were classified into vulnerable areas. Thus, the predicted risk area was categorized into High risk, Risk, and Vulnerable (Fig.8). High Risk area was found distributed at different districts amounting $\left(60.35 \mathrm{~km}^{2}\right)$. Risk areas occupy the largest prediction with a total area (2193.14 $\left.\mathrm{km}^{2}\right)$ and the vulnerable area amounted $\left(340.1 \mathrm{~km}^{2}\right)$. Rest of the study area was covered by a desert, classified 
as non-predicted region occupying the majority of the

Table 3. Density and diversity of mosquito larvae at ElFayoum districts

\begin{tabular}{|c|c|c|c|}
\hline District & Species & $\begin{array}{c}\text { Total } \\
\text { Number of } \\
\text { larvae }\end{array}$ & $\begin{array}{c}\text { Density } \\
\text { (No. of } \\
\text { larvae/dip) }\end{array}$ \\
\hline Abshawai & $\begin{array}{c}\text { Oc. caspius } \\
\text { Oc. detritus } \\
\text { Cx. pipiens }\end{array}$ & 848 & 169.6 \\
\hline Tamia & $\begin{array}{c}\text { Cx. pipiens } \\
\text { Oc. caspius } \\
\text { Oc. detritus }\end{array}$ & 366 & 73.2 \\
\hline $\begin{array}{c}\text { Cx. pipiens } \\
\text { El-Fayoum } \\
\text { Oc. detritus } \\
\text { An. multicolor }\end{array}$ & $\begin{array}{c}\text { An. sergentii } \\
\text { Cx. perexiguus } \\
\text { Oc. detritus } \\
\text { Cx. pipiens }\end{array}$ & 780 & 54 \\
\hline Atsa & Cx. pipiens & 1815 & 362.8 \\
\hline Youssef El- & $\begin{array}{c}\text { Cx. pipiens } \\
\text { Oc. detritus } \\
\text { Seddiq }\end{array}$ & 77 & 15.4 \\
\hline
\end{tabular}
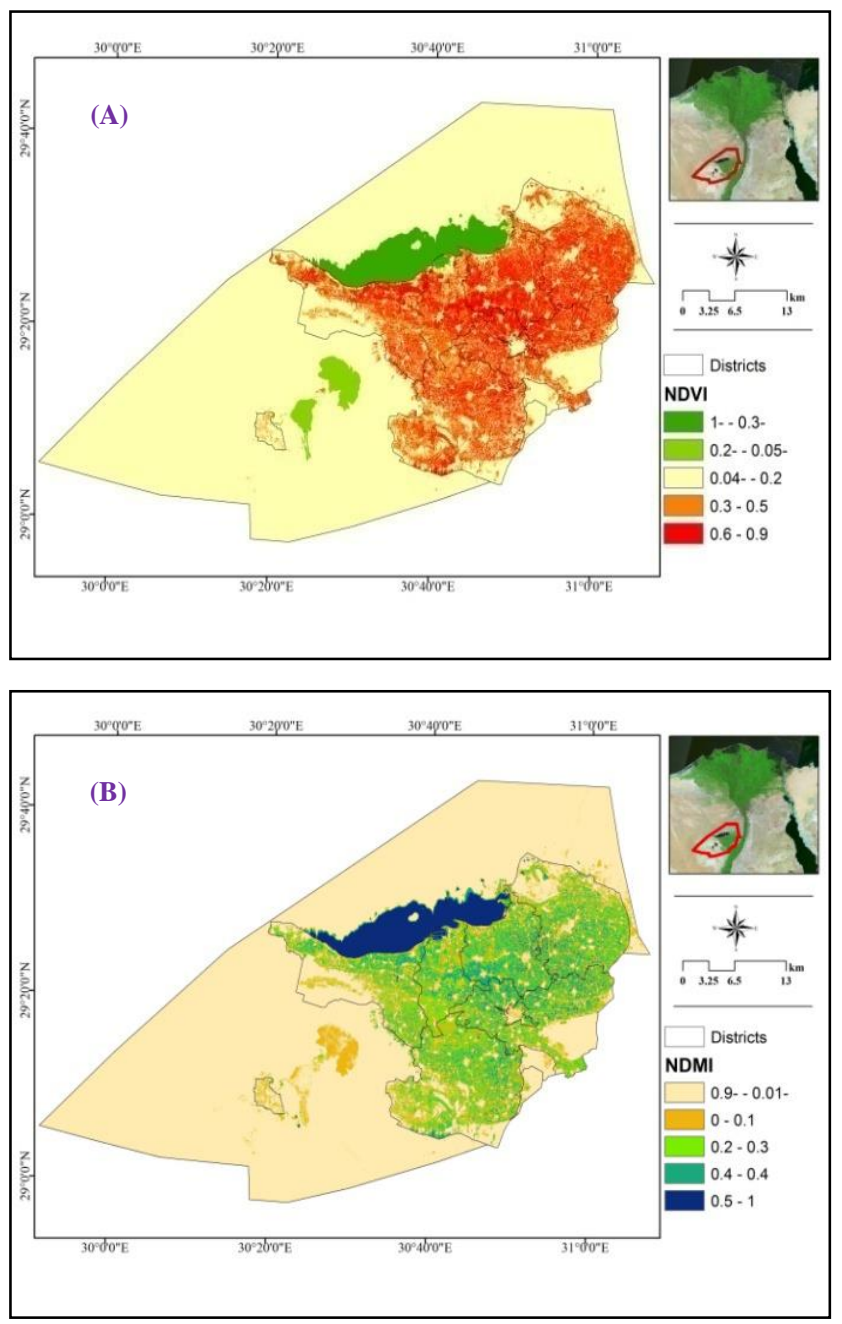

study area $\left(3201.08 \mathrm{~km}^{2}\right)$.

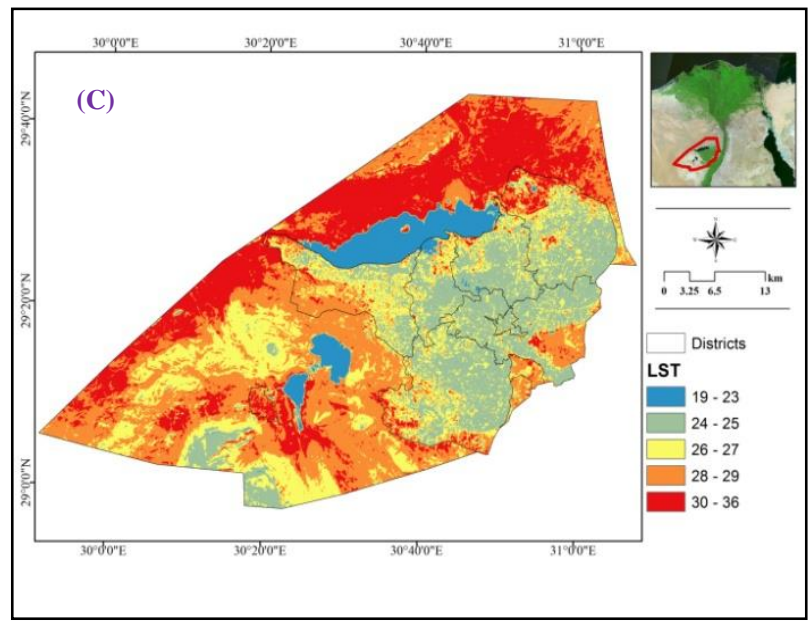

Fig. 7. Spatial distribution maps of NDVI (A), NDMI (B) and LST $\left({ }^{\circ} \mathrm{C}\right)$

Table 4. Statistics of the studied indices at different breeding habitats

\begin{tabular}{|c|c|c|c|}
\hline Stats. & NDVI & NDMI & LST \\
\hline Min & 0.18 & 0.08 & 21.75 \\
\hline Max & 0.55 & 0.28 & 28.48 \\
\hline Mean & 0.24 & 0.03 & 26.02 \\
\hline
\end{tabular}

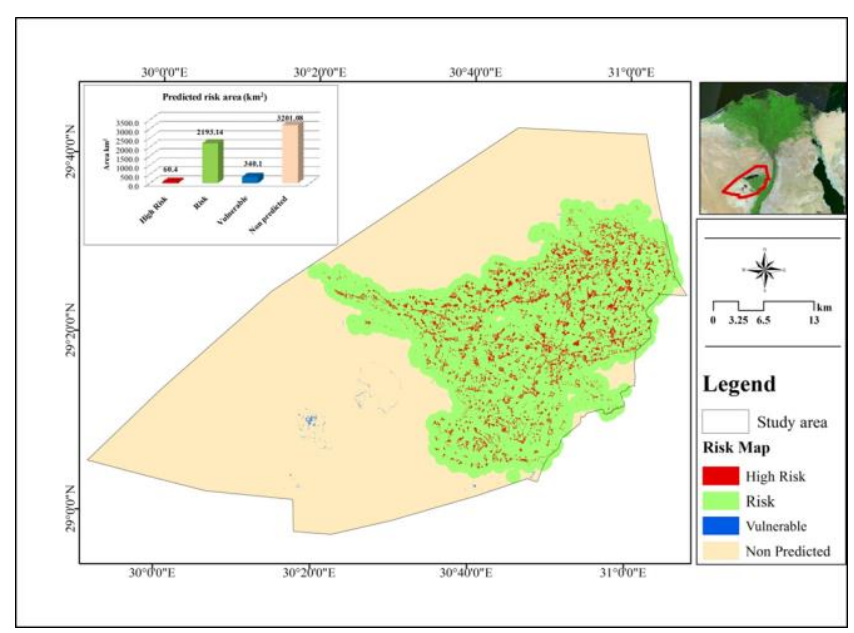

Fig. 8. Risk map of mosquito habitats

Model results showed that the highest predicted risk area was observed at Atsa district $\left(94.4 \mathrm{~km}^{2}\right)$, where the main filarial vector was distributed with high density, followed by Yousef El-Sediq $\left(81.8 \mathrm{~km}^{2}\right)$ as shown in (Fig. 9). However, the lowest prediction was reported at Abshawai district $\left(35.9 \mathrm{~km}^{2}\right)$. 


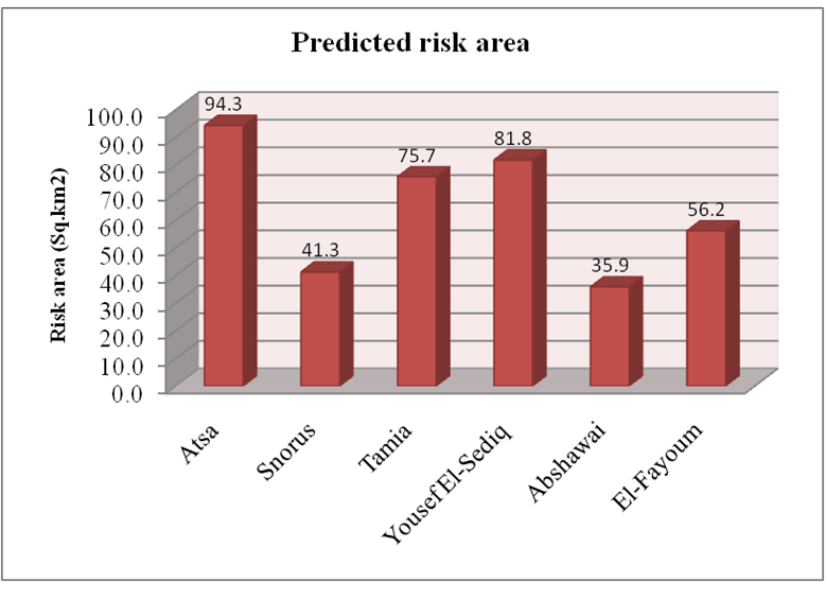

Fig. 9. Predicted risk area at El Fayoum districts

\section{Model validation}

The current study considers the model validation as one of the main steps in the accuracy assessment of the generated model. To validate the generated model and the resulted map, more than 100 sites located within the predicted area were visited and validated. The model gave satisfactory results in predicting habitats and in excluding the unsuitable sites. More than $80 \%$ of visited sites were confirmed as positive sites for mosquito breeding and proliferation. In the present study, spectral derived parameters were successfully utilized for mosquito breeding habitat identification with significant results of $80 \%$ accuracy at localities where potential larval habitats are confirmed by in-situ checks.

\section{Discussion}

El-Fayoum Governorate is environmentally suitable for mosquito breeding and therefore probability of diseases outbreak. During the studied period, three different parameters, derived from Landsat-8 image, were successfully selected to characterize mosquito breeding sites in El-Fayoum Governorate including NDVI, moisture index and temperature which have a great effect and exhibited signing relationships with mosquito proliferation [26, 27]. Remotely sensed environmental data and LULC classification as predictors resulted in efficient GIS predictive model. This data should assist control programmers to plan and implement interventions to reduce risk of mosquito epidemiology in El-Fayoum Governorate.

Mosquito fauna in El-Fayoum Governorate was represented by six species belong to three genera: $C x$. pipiens, Cx.perexiguus, Oc. caspius, Oc. detritus, An. multicolor and An. Sergentii. Cx. pipiens was the main vector disease of human filariasis (Wuchereria bancrofti) in Egypt [36-38]. Statistical analysis revealed nonsignificant difference in species occurrence and habitat type. This study investigated that NDVI and NDMI are the best predictor for Cx. Prexiguus; with regression of 0.81 and 0.87 respectively.
The two species; $C x$. pipiens, $C x$. perexiguus are coexisted because of the similar feeding preferences. In the study area, it is observed that $C x$. pipiens was present with high density and collected from stagnant polluted drains associated with human activities. This is compatible with [39, 40]. Most polluted breeding sites urge the spread of more culicines while these sites don't favor anopheline proliferation [41]. The main filariasis vector presents in various breeding habitats [42] especially in domestic drainage canals, and small irrigation canals which are numerous within the study area. The two species Oc. caspius and An. multicolor preferred brackish pools and seepage habitats in the study area [43], while An. sergentii mainly breed in water either fresh or moderate salinity, but prefers clean, shallow, stagnant or slow-moving water with vegetation especially the small water collections in grassy areas.

The potential habitats of mosquito vectors in ElFayoum Governorate are drains, Sewage, and Seepage. Sewage and domestic drainage canals were observed close to residential areas; this indicates that the poor sanitation of the most locations in the study area appears to be responsible for the abundance of mosquito habitats, agreed with [44] who stated that the densities of vectors increased with rapid urbanization in El- Fayoum districts.

Finally, the precise spatial distribution mapping of mosquito breeding habitats is very necessary for costeffective control of vectors and facilitate the assessment of areas of high vector abundance that are located under risk of potential diseases transmission $[14,45,46]$.

In Egypt, there are different environmental applications of remotely sensed data and GIS which are extensively utilized for assessing, modeling and monitoring different environmental variables and problems [e.g. 47-59]. Adding the application of mosquito studies will reinforce sustainability and vulnerability studies which will be adopted in the upcoming studies for supporting the Egyptian developmental plans.

\section{Conclusion}

This study has provided data on larval habitats of mosquitoes in El-Fayoum Governorate. Atsa and Abshawai represents the highest two districts in the Governorate located under environmental risk of potential filariasis disease spread. Results presented here demonstrate the potential for geospatial techniques to identify larval habitats on a large geographic area and modeling the distribution of mosquito habitats that help in planning optimal vector control. With the increasing of mosquito habitats as well as evidence of emerging diseases, multi-year data for spatial/temporal information on mosquito habitats is required since the environmental factors are subject to continual change, to predict mosquito density and mitigate the area under risk of emergence/re-emergence diseases.

The authors express their deep appreciations to the United States Geological Survey for supporting Landsat image data 
and to National Authority for Remote Sensing and Space Sciences (NARSS) for sponsoring the study and development project titled "Regional Assessment of Environmental Vulnerability and Potentiality in El-Fayoum Governorate using Remote Sensing and GIS".

\section{References}

1. H.K. Bassiouny Determination of epidemiological factors causing the persistence of malaria transmission in Fayoum goveronorate, final report Alexandria, WHO Reginal Office for the Eastern Mediterranean (1996)

2. H.K. Bassiouny, Bioenvironmental and meteorological factors related to the persistence of malaria in Fayoum goveronorate a retrosoective study. East. Medit. Health J., 7(6): 895-906 (2001).

3. S. M. Dahesh H. I. Mostafa, Reevaluation of malaria parasites in El-Fayoum Governorate, Egypt using rapid diagnostic tests (RDTS), J. Egypt. Soc. Parasitol. (JESP), 45(3): 617 - 628 (2015)

4. WHO Global Malaria Programme, World Health Organization, Geneva, Switzerland (2012b).

5. K.C. Ernst, S.O. Adoka, D.O. Kowuor, M.L. Wilson, C.C. John, Malaria hotspot areas in a highland Kenya site are consistent in epidemic and non-epidemic years and are associated with ecological factors, Malar. J. 5:78 (2006).

6. M. Harb, (Malaria situation in Egypt. Annual report, Ministry Of Health and Population, Cairo), National project for the development of the northern Nile Valley (1995-2017), Cairo, Ministry of Planning (1994)

7. S. El Said, J.C. Beier, M. Kenawy, Z. S. Morsy A. I. Merdan, Anopheles population dynamics in two malaria endemic villages in Faiyum Governorate, Egypt. J. Am. Mosq. Control Assoc. 2: 158- 163 (1986)

8. U. Kitron, A. Spielman Suppression of transmission of malaria through source reduction: antianopheline measures applied in Israel, the United States, and Italy. Rev. Infect. Dis. 11: 391-406 (1989)

9. G. F. Killeen, U. Fillinger, B. G. J. Knols, Advantages of larval control for African malaria vectors: low mobility and behavioural responsiveness of immature mosquito stages allow high effective coverage. Malar. J. 1, 8.10.1186/1475-2875-1-8 (2002)

10. S. Agarwal, S. Sikarwar, D. Sukumaran, Application of RS GIS in Risk area assessment for mosquito borne diseases - a case study in a part of Gwalior City (M.P.). IJATER 2 (1) 4, (2012).

11. R.O. Hayes, E.L. Maxwell, C.J. Mitchell, T.L. Woodzick, Detection, identification and classification of mosquito larval habitats using remote sensing scanners in earth orbiting satellites. Bull, World Health Organ. 63: 361-374 (1985)

12. R.C. Sharma, V.K. Saxena, M. Bharadwaj. R.S. Sharma, T. Verghese, K.K. Datta, An outbreak of Japanese encephalitis in Haryana. J. Commun Dis., 23(2): 168-9 (1990)

13. R.K. Washino, B.L. Wood, Application of remote sensing to vector arthropod surveillance and control. Am. J. Trop. Med. Hyg. 50 (6 Suppl): 134-144. (1994).

14. P.E. Dale, S.A. Ritchie, B.M. Territo, C.D. Morris, A. Muhar, B.H. Kay, An overview of remote sensing and GIS for surveillance of mosquito vector habitats and risk assessment, J. Vector. Ecol. 23: 54-61 (1998)
15. S.I. Hay, R.W. Snow, D.J. Rogers, Predicting malaria seasons in Kenya using multi-temporal meteorological satellite sensor data, Trans. R. Soc. Trop. Med. Hyg. 92: 12-20 (1998).

16. S.I. Hay J.J. Lennon, Deriving meteorological variables across Africa for the study and control of vector-borne disease. A comparison of remote sensing and spatial interpolation of climate, Trop. Med. Int. Health, 4(1): 5871 (1999)

17. A. Hassan, M Kenawy, H. Kamal, A .Abdel Sattar, M. Sowilem, GIS-based prediction of malaria risk in Egypt. La Revue de Santé de la Méditerranée orientale, 9 (4): 548-558 (2003)

18. A.N. Hassan, H.M. Onsi, Remote sensing as a tool for mapping mosquito breeding habitats and associated health risk to assist control efforts and development plans: a case study in Wadi El Natroun, Egypt. J. Egypt. Soc. Parasitol., 34 (2): 367-382 (2004)

19. L. Zou, S.N. Miller, E.T. Schmidtmann, Mosquito larval habitat mapping using remote sensing and GIS: Implications of Coalbed methane development and west Nile virus, J. Med. Entomol., 43(5): 1034-1041 (2006)

20. S. Kalluri, P. Gilruth, D. Rogers, M. Szczur, Surveillance of arthropod vector-borne infectious diseases using remote sensing techniques: a review. PLoS Pathog., 3 (10):e116 (2007)

21. A. Hanafi-Bojd, H. Vatandoost, M. Oshaghi, Z. Charrahy, A. Haghdoost, M. Sedaghat, F. Abedi, M. Soltani, A. Raeisi, Larval habitats and biodiversity of anopheline mosquitoes (Diptera: Culicidae) in a malarious area of southern Iran. J. Vector Borne Dis. 49: 91-100 (2012)

22. M. Palaniyandi, T. Mariappan, Containing the spread of malaria with geospatial tech, Geospatial World Weekly, acquired on 27 Feb. 2015, 8, (9) (2012)

23. M. Palaniyandi, The environmental aspects of dengue and chikungunya outbreaks in India: GIS for epidemic control, Int. J. Mosq. Res. 1 (2): 35-40 (2014)

24. M. Palaniyandi, GIS for rapid epidemiological mapping and health-care management with special reference to filariasis in India, Int. Med. Sci. Publ. Health 4 (8): 11411146 (2015)

25. M. M. Sowilem, Defining spatial distribution of mosquito breeding sites and areas under risk using remote sensing GIS integration. J. Biotechnol Biomater, 3 (5) 76 (2014).

26. M. Sowilem, A. El-Zeiny, W. Atwa, M. Elshaier, A. ElHefni, Assessing and Monitoring Spatiotemporal Distribution of Mosquito Habitats, Suez Canal Zone. Asian J. Env. \& Ecol., 4(2): 1-13 (2017)

27. A. El-Zeiny, A. El-Hefni, M. Sowilem, Geospatial technique for environmental modeling of breeding habitats at Suez Canal Zone, Egypt, The Egypt. J. of Remote Sensing and Space Sciences. 20: 283-293 (2017)

28. M. J. Nelson, The role of sampling in vector control, Am. J. Trop. Med. Hyg., 50:145-150 (1994)

29. A. Gad, A. El-Zeiny, Spatial Analysis for Sustainable Development of El Fayoum and Wadi El Natrun Desert Depressions, Egypt with the Aid of Remote Sensing and GIS, J. Geog., Env. and Earth Sci. Int. 8(3): 1-18 (2016)

30. Euroconsult, Environmental profile, Fayoum Governorate, Egypt. Al-Shorouk Press, Cairo (1992)

31. W.F. Erian, An approach to apply the American Soil Taxonomy on some soils of Egypt. MSc thesis, Faculty of Agriculture, Cairo University, Egypt (1982) 
32. R.E. Harbach, The mosquitoes of the subgenus Culex in the southwestern Asia and Egypt (Diptera: Culicidae), Contrib. Am. Entomol. Inst. (Ann Arbor) 24, 240 (1988)

33. J.W. Rouse, R.H. Haas, J.A. Schell, D.W. Deering, Monitoring vegetation systems in the Great Plains with ERTS. In: Third ERTS Symposium, NASA SP-351, 1: 309-317 (1973)

34. C. Duran, Effects on drought and vegetation of topography in the Tarsus River Basin (Southern Turkey). Int. J. Hum. Sc., 12(2): 1853-1866 (2015)

35. M. D. Shahid-Latif, Land Surface Temperature Retrieval of Landsat-8 Data Using Split Window Algorithm- A Case Study of Ranchi District IJEDR, 2 (4): 3840-3849 (2014)

36. S. S. Rashed, Survey of mosquito species in Sharkiya Governorate with special reference to population density of culicids transmitting filarial. M.Sc. Thesis, Fac. Sci. Zagazig Univ. 181pp. (1981)

37. A. M. Gad, M. M. Hassan, S. EI-Said, M. L. Moussa, O. L. Wood, Rift Valley fever transmission by different Egyptian mosquito species. Trans. Roy. Soc. Trop. Med. Hyg., 81:694-8 (1987)

38. Y. Abdel-Hamid, M.I. Soliman, K. M. Allam, Spatial distribution and abundance of culicine mosquitoes in relation to the risk of filariasis transmission in Sharkia Governorate, Egypt, Egypt. Acad. J. Biolog. Sci., 1(lE): 39-48. (2009)

39. S.E. Ammar, M.A. Kenawy, H.A. Abd El Rahman, A.M. Gad, A.F. Hamed Ecology of the mosquito larvae in urban environments of Cairo Governorate, Egypt, J. Egypt. Soc. Parasitol., 42: 191-202 (2012)

40. A. Tran, C. Ippoliti, T. Balenghien, A. Conte, M. Gely, P. Calistri, M. Goffredo, T. Baldet, V. Chevalier, A geographical information system-based multicriteria evaluation to map areas at risk for Rift Valley fever vector-borne transmission in Italy, Transboundary Emerg. Dis., 60: 14-23 (2013)

41. C. Oringanje, A.A.A. Alaribe, A.O. Oduola, O.A. Oduwole, A.O. Adeogun, M.M. Meremikwu, T. S. Awolola, Vector abundance and species composition of Anopheles mosquito in Calabar, Nigeria, J. Vector Borne Dis., 48:171-173 (2011)

42. M.R. Harb, A.M. Faris, O.N. Gad, R. Hafez, A.A. Ramzy, A.A. Buck, The resurgence of lymphatic filariasis in the Nile Delta, Bull. World Health Org., 71 (1): 49-54 (1993)

43. R.E. Harbach, B. A. Harrison, A.M. Gad, M.A. Kenawy, S. El-Said, Records and notes on mosquitoes (Diptera: Culicidae) collected in Egypt, Mosq. Syst., 20:317-342 (1988)

44. A.B, Knudsen, R. Slooff, Vector-borne disease problems in rapid urbanization: new approaches to vector control. Bull World Health Organ, 70(1):1-6 (1992)

45. M. C. Thomson, S. J. Connor, Environmental Information Systems for the control of Arthropoda vectors of diseases, Med. Vet. Entomol., 14 (3): 227-244 (2000)

46. S. O. Vanwanbeke, P. Somboon, R. Harbach, M. Isenstadt, E. F. Lambin, C. Walton, R. K. Butlin, Landscape and land cover factors influence the presence of Aedes and
Anopheles larvae, J. Med. Entomol., 44 (1): 133-144 (2007)

47. A. H. El Nahry, E. S. Mohamed, Potentiality of land and water resources in African Sahara: a case study of south Egypt, Envir. Earth Sci., 63 (6): 1263-1275 (2011).

48. E. S. Mohamed, Spatial assessment of desertification in north Sinai using modified MEDLAUS model. Arabian J. of Geosciences, 6 (12): 4647-4659 (2013).

49. E. S. Mohamed, A. Belal, A. Saleh, Assessment of land degradation east of the Nile Delta, Egypt using remote sensing and GIS techniques, Arabian J. of Geosciences, 6 (8): 2843-2853 (2013).

50. F. Amato, J. Havel, A. Gad, A. El-Zeiny, Remotely Sensed Soil Data Analysis Using Artificial Neural Networks: A Case Study of El-Fayoum Depression, Egypt, ISPRS Inter. J. of Geo-Information, 4(2): 677-696 (2015).

51. M. Abu-Hashim, E. S. Mohamed, A. E. Belal, Identification of potential soil water retention using hydric numerical model at arid regions by land-use changes, International Soil and Water Conservation Research, 3(4): 305-315 (2015).

52. M. Abu-hashim, M. Elsayed, A. E. Belal, Effect of landuse changes and site variables on surface soil organic carbon pool at Mediterranean Region, J. of Afr. Earth Sci., 114: 78-84 (2016).

53. E. S. Mohamed, A. M. Ali, M. A. El Shirbeny, A. A. El Razek, I.Y. Savin, Near infrared spectroscopy techniques for soil contamination assessment in the Nile Delta. Eurasian soil science, 49(6): 632-639 (2016)

54. A. A. Hammam, E.S. Mohamed, Mapping soil salinity in the East Nile Delta using several methodological approaches of salinity assessment. The Egyptian Journal of Remote Sensing and Space Science, in press, https://doi.org/10.1016/j.ejrs.2018.11.002 (2018)

55. E.S. Mohamed, A. Ali, M. El-Shirbeny, K. Abutaleb, S.M. Shaddad, Mapping soil moisture and their correlation with crop pattern using remotely sensed data in arid region, The Egyptian J. of Remote Sensing and Space Science, in press, https://doi.org/10.1016/j.ejrs.2019.04.003 (2019)

56. E. S. Mohamed, M. AbdelRahman, B. Schütt, R. Lasaponara, Evaluating the effects of human activity over the last decades on the soil organic carbon pool using satellite imagery and GIS techniques in the Nile Delta Area, Egypt, Sustainability, 11(9), 2644 (2019)

57. M. A. AbdelRahman, A. Shalaby, E. S. Mohamed, Comparison of two soil quality indices using two methods based on geographic information system, The Egyptian J. of Remote Sensing and Space Science, 22(2): 127-136 (2019)

58. A. M. El-Zeiny, S. F. Elbeih, GIS-Based Evaluation of Groundwater Quality and Suitability in Dakhla Oases, Egypt, Earth Syst Environ, 3(3): 507-523 (2019)

59. A.M. El-Zeiny, H. A. Effat, Environmental analysis of soil characteristics in El-Fayoum Governorate using geomatics approach. Environ Monit Assess, 191: 463 (2019) 